\title{
The Effects of Loneliness on Menopausal Symptoms
}

\author{
Fadime Bayri Bingol ${ }^{1}$ (D), Meltem Demirgoz Bal ${ }^{1}$ (D), Tugba Yilmaz Esencan² (iD, Done Ertugrul Abbasoglu² (iD, Begum Aslan ${ }^{1}$ (iD \\ ${ }^{1}$ Marmara University, Health Sciences Faculty, Midwifery Department, Istanbul, Turkey. \\ ${ }^{2}$ Zeynep Kamil Women and Child Diseases Research and Training Hospital, Istanbul, Turkey.
}

Correspondence Author: Fadime Bayri Bingol

E-mail: fadimebayri@gmail.com

Received: 11.11 .2018

Accepted: 28.02 .2019

\begin{abstract}
Objectives: This study was carried out to investigate the effect of menopausal symptoms on the loneliness of women in the menopausal period. Methods: The study sample consisted of 546 women who applied to the menopause polyclinic of a state hospital in Istanbul and agreed to participate in the study. Data were collected using the Personal Information Form, UCLA Loneliness Scale and Menopausal Symptom Rating Scale (MRS).

Results The mean age of the women included in the study was $52.70 \pm 6.39$. The mean scores of menopausal symptoms of women included in the study; were found to be higher in women with low education level $(p=0.001)$, women with big family structure $(p=0,002)$ and women with low income $(p=0,001)$. It was determined that women with less education $(p=0,015)$, women not working ( $p=0,001)$ and women with low income $(p=0,001$ ) were found to have higher mean loneliness scores. Correlation analysis revealed that the mean scores of menopausal symptoms were increased $(p=0,000)$ as the loneliness level average of women increased. Women with the most severe mean scores of menopausal symptoms were found to have the highest mean level of loneliness $(p=0,000)$.

Conclusion: Women with high levels of loneliness were found to have experienced severe menopausal symptoms. It was determined that as women's level of loneliness increased, menopausal symptoms increased.

Keywords: Menopause, loneliness, women's health
\end{abstract}

\section{INTRODUCTION}

Women spend nearly $1 / 3$ of their lives in menopause and the period after menopause due to prolonged life span (1$3)$. In this period, women live a lot of change in their family, work and social lives besides some roles and responsibilities as wife, mother, business woman, grandmother and friend. Women in the menopausal period are exposed to significant physiologic changes concurrent with social changes. Radical family and social environment changes (divorce, children leaving house, being a grandmother, lost relatives, etc.) with increased age and in the beginning of the menopausal period could prolong the adaptation period to menopause and pose a developmental crisis. A crisis that cannot be managed well could cause feeling vasomotor and emotional symptoms deeply, decrease the productivity of women and increase costs in healthcare (4-6). The main physiological changes in the menopausal period are due to the effect of decreasing follicle activity and loss of circulating estrogen. However, physiological changes cause menopausal symptoms of different severity depending on the cultural differences in each population. When menopause is perceived as loss of femininity, symptoms could be more frequent and severe; however, when it is perceived as a process that leads the requirement of contraceptives to disappear, the severity of symptoms may be lower $(4,7)$. For this reason, the meaning of menopause for the women is quite important in terms of the severity of symptoms $(4,7-11)$.

Although menopause is a natural and physiological process, it needs follow up and support due to its risks. Because of the importance of estrogen in mood and cognitive regulation, menopause is a powerful predictor of depression and mood symptoms in middle-aged women. In this period, the most common symptom among mood symptoms is the feeling of loneliness. Loneliness is a painful and undesirable feeling in itself, but it also leads to many different problems. Loneliness could lead to a lot of negative health problems such as particularly - depression and sleep problems, disturbance in HPA (Hypothalamus-pituitary-adrenal) axis and cardiovascular risks (12-16). It is very important to reduce the feelings of loneliness and share feelings in menopause. When literature is reviewed, it is seen that studies that have investigated the effects of loneliness on menopausal symptoms $(17,15)$ are limited. This study aimed to evaluate the effects of loneliness on menopausal symptoms in women in their menopausal period.

\section{METHODS}

This study is a cross sectional and descriptive study.

\subsection{Participants}

This study was conducted with women who applied to the menopause polyclinic between October 2016 and October 
2017, were voluntary to participate to the study, spoke Turkish and did not have any communication problems. All women included in the study were in the postmenopausal period. The mean age of menopause was $45.37 \pm 5.74$ (Min:30Max:57) years. Data were collected from a total of 570 women. After excluded the forms that were not completely filled out, the sample consisted of 546 women. The study was conducted at Zeynep Kamil Women and Child Diseases Research and Training Hospital, which is the largest Women and Child Diseases Hospital in Istanbul's Anatolian side. Istanbul is the most crowded city in Turkey which receives immigration the most. It is foreseen that the diverse set of data obtained due to the public service of the hospital where the study was performed, would reflect the characteristics of the country as a whole.

Before the study, permission was obtained from Zeynep Kamil Woman and Child Diseases Research and Training Hospital Clinical Research Ethical Committee (171-12.23.2016). Moreover, women who met the criteria of the study were informed about the objective, method and contributions of the study, and their verbal consent was also obtained. They were explained that they could leave the study when they wanted.

\subsection{Data collection and tools}

All participants were asked to fill in the questionnaires by face-to face interviews: Sociodemographic Information Form, Menopause Rating Scale (MRS) Turkish Version and UCLA Loneliness Scale Turkish Version.

The Sociodemographic Information From was prepared in relation to the literature by the researchers. The form included 13 questions on the participants' age, marital status, occupational status, number of births, menopause characteristic, etc. All menopausal women who applied to the polyclinic due to menopausal symptoms in the premenopausal, perimenopausal and postmenopausal periods were included in the study. The menopausal periods were determined by using the WHO's criteria.

The Menopause Rating Scale (MRS) has 11 items that are scored as a Likert-type scale. The scale can determine the symptoms of menopause as somatic, psychological and urogenital, and at the same time, provide information on the quality of life of the women. A higher total score in the scale indicates an increase in the severity of menopausal symptoms from one side, while it affects the quality of life negatively on the other. The validity-reliability study of the scale in Turkey was conducted by Gürkan (18). The Cronbach's Alpha value of the scale was 0.96 in this study.

The University of California Los Angeles Loneliness Scale (UCLA-LS) has 20 items as a Likert-type scale. 10 items are positive sentences showing satisfaction from social relationships, and 10 items include negative sentences showing dissatisfaction from social relationships. The validity-reliability study of the scale in Turkey was conducted by Demir (19). The Cronbach's Alpha value of the scale was 0.91 in this study.

\subsection{Statistical Analysis}

After all data were collected, they were analyzed by using the Statistical Package for Social Science (SPSS), version 21.0. Score means $\pm S D$ for MRS and UCLA-LS and frequency and percentages of the demographic characteristics were determined. The data were tested for suitability for normal distribution by histogram and One-Sample KolmogorovSmirnov Test. The statistical significance of the scores for MRS and UCLA-LS were compared with student's t-test and one-way ANOVA in terms of the sociodemographic characteristics. Menopause total score and UCLA-LS total score were evaluated by using Pearson Correlation Analysis. One-way ANOVA test was used to evaluate menopausal complaint levels and loneliness scores.

\section{RESULTS}

A total of 546 women between 38 and 65 years of age participated in this study. Their mean age was $52.70 \pm 6.39$ (min:38-max:65), and $83.2 \%$ of them $(n=454)$ were in the spontaneous menopause group. The demographic characteristics of the women are seen in Table 1.

Table 1. Participants characteristics $(n=546)$

\begin{tabular}{|c|c|c|}
\hline Characteristics; & $\%$ & $n$ \\
\hline \multicolumn{3}{|l|}{ Education level } \\
\hline$\leq 8$ & 73,8 & 403 \\
\hline$>8$ years & 26,2 & 143 \\
\hline \multicolumn{3}{|l|}{ Marital status } \\
\hline Single & 34,8 & 190 \\
\hline Married & 65,2 & 356 \\
\hline \multicolumn{3}{|l|}{ Family type } \\
\hline Small family & 83,3 & 455 \\
\hline Big family & 16,7 & 91 \\
\hline \multicolumn{3}{|l|}{ Presently working } \\
\hline Yes & 25,6 & 140 \\
\hline No & 74,4 & 406 \\
\hline \multicolumn{3}{|l|}{ Income status } \\
\hline Low & 11,5 & 63 \\
\hline Balanced & 75,3 & 411 \\
\hline Income more than expense & 13,2 & 72 \\
\hline \multicolumn{3}{|l|}{ Menopause reason } \\
\hline Spontaneous & 83,2 & 454 \\
\hline Surgical & 16,8 & 92 \\
\hline
\end{tabular}

It was determined with the student's t-test that the mean menopause complaint scores were higher in the women whose education levels were 8 years and shorter $(p=0.001)$, who lived in a big family ( $p=0.002)$, and did not work at a regular job $(p=0.001)$. The MRS score was lower in the women who went through menopause by surgery $(p=0.001)$. Moreover, it was found with the one-way ANOVA test that the mean MRS score was higher in the women with low income $(p=0.001)$ (Table 2$)$. 
Table 2. Comparing characteristics of participants with MRS scores $(n=546)$

\begin{tabular}{|c|c|c|c|c|}
\hline Characteristics; & $\%$ & $n$ & MSD & $p$ \\
\hline Education level & & & Mean $\pm S D^{*}$ & \\
\hline$\leq 8$ & 73,8 & 403 & $21,64 \pm 13,76$ & $p=0,001$ \\
\hline$>8$ years & 26,2 & 143 & $10,96 \pm 12,63$ & $\mathrm{t}=8,14^{* *}$ \\
\hline \multicolumn{5}{|l|}{ Marital status } \\
\hline Single & 34,8 & 190 & $19,38 \pm 14,51$ & \multirow{2}{*}{$\begin{array}{c}p=0,52 \\
t=0,63 * *\end{array}$} \\
\hline Married & 65,2 & 356 & $18,56 \pm 14,14$ & \\
\hline \multicolumn{5}{|l|}{ Family type } \\
\hline Small family & 83,3 & 455 & $18,02 \pm 13,89$ & \multirow{2}{*}{$\begin{array}{l}p=0,002 \\
t=3,04 * *\end{array}$} \\
\hline Big family & 16,7 & 91 & $22,97 \pm 15,41$ & \\
\hline \multicolumn{5}{|l|}{ Presently working } \\
\hline Yes & 25,6 & 140 & $12,78 \pm 12,50$ & \multirow{2}{*}{$\begin{array}{l}p=0,001 \\
t=6,01 * *\end{array}$} \\
\hline No & 74,4 & 406 & $20,94 \pm 14,24$ & \\
\hline \multicolumn{5}{|l|}{ Income status } \\
\hline Low & 11,5 & 63 & $26,00 \pm 9,75$ & \multirow{3}{*}{$\begin{array}{c}\mathrm{p}=0,001 \\
\mathrm{~F}=9,997^{* * *}\end{array}$} \\
\hline Balanced & 75,3 & 411 & $18,24 \pm 14,90$ & \\
\hline Income more than expense & 13,2 & 72 & $16,04 \pm 11,88$ & \\
\hline \multicolumn{5}{|l|}{ Menopause reason } \\
\hline Spontaneous & 83,2 & 454 & $20,50 \pm 13,65$ & \multirow{2}{*}{$\begin{array}{c}p=0,001 \\
t=6,22 * *\end{array}$} \\
\hline Surgical & 16,8 & 92 & $10,68 \pm 14,49$ & \\
\hline
\end{tabular}

*Mean; Average SD: Standard deviation, ** Student $t$ test, ***One-way ANOVA

It was determined as a result of the student's t-test that the mean loneliness scores were higher in the women whose education statuses were 8 years and shorter $(p=0.015)$, and did not work at a regular job $(p=0.001)$. Additionally, it was found by the one-way ANOVA test that the mean loneliness score was higher in the women with low income $(p=0.001)$ (Table 3).

Table 3. Comparing characteristics of participants with UCLA - LS scores $(n=546)$

\begin{tabular}{|c|c|c|c|c|}
\hline Characteristics; & $\%$ & $\mathrm{n}$ & UCLA & $\mathrm{p}$ \\
\hline Education level & & & Mean $\pm S D^{*}$ & \\
\hline $\mid \leq 8$ & 73,8 & 403 & $48,15 \pm 14,84$ & $p=0,015$ \\
\hline$>8$ years & 26,2 & 143 & $44,62 \pm 14,56$ & $\mathrm{t}=2,44^{* *}$ \\
\hline \multicolumn{5}{|l|}{ Marital Status } \\
\hline \begin{tabular}{l|l} 
Single \\
\end{tabular} & 34,8 & 190 & $48,85 \pm 15,45$ & \multirow{2}{*}{$\begin{array}{c}p=0,15 \\
t=1,44^{* *}\end{array}$} \\
\hline Married & 65,2 & 356 & $46,55 \pm 14,47$ & \\
\hline \multicolumn{5}{|l|}{ Family type } \\
\hline \begin{tabular}{l|l} 
Small family \\
\end{tabular} & 83,3 & 455 & $46,80 \pm 14,64$ & \multirow{2}{*}{$\begin{array}{c}p=0,13 \\
t=1,48^{* *}\end{array}$} \\
\hline Big family & 16,7 & 91 & $49,32 \pm 15,66$ & \\
\hline \multicolumn{5}{|l|}{ Presently working } \\
\hline \begin{tabular}{l|l} 
Yes \\
\end{tabular} & 25,6 & 140 & $43,10 \pm 14,15$ & \multirow{2}{*}{$\begin{array}{l}p=0,000 \\
t=3,86^{* *}\end{array}$} \\
\hline No & 74,4 & 406 & $48,65 \pm 14,81$ & \\
\hline \multicolumn{5}{|l|}{ Income status } \\
\hline \begin{tabular}{l|l} 
Low \\
\end{tabular} & 11,5 & 63 & $50,12 \pm 15,12$ & \multirow{3}{*}{$\begin{array}{c}\mathrm{p}=0,001 \\
\mathrm{~F}=6,716^{* * *}\end{array}$} \\
\hline Balanced & 75,3 & 411 & $47,76 \pm 14,90$ & \\
\hline \begin{tabular}{|l|l|}
$\begin{array}{l}\text { Income more than } \\
\text { expense }\end{array}$ \\
\end{tabular} & 13,2 & 72 & $41,63 \pm 12,86$ & \\
\hline \multicolumn{5}{|l|}{ Menopause reason } \\
\hline \begin{tabular}{l|l} 
Spontaneous \\
\end{tabular} & 83,2 & 454 & $46,67 \pm 14,68$ & \multirow{2}{*}{$\begin{array}{l}\mathrm{p}=0,053 \\
\mathrm{t}=1,94^{* *}\end{array}$} \\
\hline Surgical & 16,8 & 92 & $49,95 \pm 15,35$ & \\
\hline
\end{tabular}

*Mean; Average SD: Standard deviation, ** Student $t$ test, ***One-way ANOVA

In the correlation analysis, it was found that menopause complaint levels increased with increased loneliness scores $(p=0.000 r=0.27)$, and as a result of the one-way ANOVA test, it was determined that the group that had the most severe menopause symptoms also had the highest loneliness scores ( $p=0.000 \quad F=16.745$ ) (Table 4). In explanation of loneliness levels in the women, the significance of menopause complaint levels was confirmed by the regression analysis ( $F=43.499$ $\mathrm{p}=0.000$ ). The values related to the regression (Beta) coefficient $(t=6.595 p=0.000$ ) were statistically significant.

Table 4. Comparing MRS with UCLA-LS Scores $(n=546)$

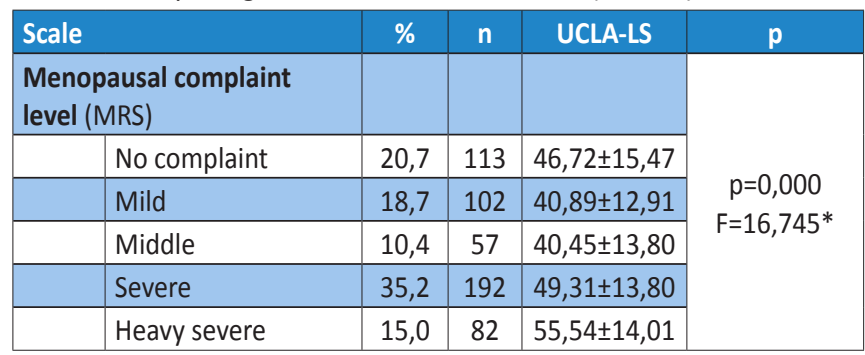

* One-way ANOVA

The mean MRS score of the women was 18.84 \pm 14.26 (Min:0, Max:44). It was determined that the somatic, psychological and urogenital subscale scores in the women increased with increased loneliness scores $(p=0.000)$ (Table 5).

Table 5. MRS with UCLA-LS Score Means of participants $(n=546)$

\begin{tabular}{|c|c|c|c|c|c|}
\hline & \multicolumn{4}{|c|}{ MRS } & \multirow{2}{*}{ UCLA } \\
\hline & Total & Somatic & Psychological & Urogenital & \\
\hline Mean \pm SD & $18,84 \pm 14,26$ & $\begin{array}{l}6,95 \pm 5,20 \\
r=, 23 / p=000^{*}\end{array}$ & $\begin{array}{l}8,86 \pm 7,02 \\
r=, 24 / p=000 *\end{array}$ & $\begin{array}{l}3,03 \pm 2,91 \\
r=, 32 / p=000^{*}\end{array}$ & $\begin{array}{l}47,22 \pm 14,83 \\
r=, 27 / p=0.000 *\end{array}$ \\
\hline
\end{tabular}

*Comparing UCLA and MRS sub scales by pearson correlation

\section{DISCUSSION}

When the literature is screened, it is seen that there are limited studies that investigated menopausal complaint levels and loneliness in women in their menopausal period. In this study, it was determined that loneliness increased menopausal complaint levels similar to the results of the study by Fernández et al. (15). In the study by Fernández et al. (15), the mean MRS score $(10.3 \pm 4)$ was lower than our result. Besides this, the mean UCLA score was three times higher (47.22 \pm 14.83$)$ than the other study (18.4 \pm 12.75$)$, as an unexpected result. A high mean UCLA score is an unexpected situation for Turkish women. Being alone in Turkish society is not an accustomed status. From childhood to old age, life continues in a strong social support network, where family and social and environmental connections are close. However, women could be traumatized, and menopausal period could be more difficult for them because of some reasons like the effect of migration from the village to the city, increased education level, increased number of working women, living in a small family type instead of traditional big family, increased number of old people and becoming alone by children leaving the house. It may also be due to the fact that women could undertake a lot of roles in this period, and 
some economic inadequacies and limited social environment could make them more self-enclosed (20). Indeed, culturally determined attitudes are reported to affect menopause perception and experience $(10,21)$.

According to Fernández et al. (15), loneliness is a common complaint, while women go through menopause, and the menopausal period is more difficult in women who have high levels of loneliness. Loneliness is also a trigger factor for depression $(16,22)$. Loneliness could cause very negative health problems such as sleep problems and cardiovascular problems (14-16,23). Sharing loneliness could decrease the development of depression and make an important contribution to the healthcare system (22). It is debated whether depression is a cause or effect in the menopausal period (24). Although it is suggested that menopause could not lead to psychiatric disorders by itself (25), going through menopause increases the risk of depressive symptoms (2632). Lee and Kim (33) reported that women who had high menopausal complaint levels were at risk of depression by three times more. Retirement, children leaving home and losing relatives are other important situations that should be considered in depression within the menopausal period (34). However, it was a limitation of the study that depressive symptoms in women were not investigated here. Thus, relationships between loneliness, depressive symptoms and menopausal symptoms could not be determined.

In similarity to the literature, menopausal symptoms increased with decreased education status $(20,26,33,35)$, and they caused more negative mental health $(11,29)$. Additionally, in these people, social support levels were lower (7). It is believed that, as the level of education of women increases, this may lead to economic prosperity and expansion of social environments and the opportunity to express their feelings.

When the literature was reviewed, it was suggested based on some studies the family type did not affect the severity of menopausal symptoms $(20,36)$. In another study, it was found that incompatible familial relations could predict depressive symptoms (37). Besides this, another study determined that perceived social support from the family decreased menopausal symptoms (38). In our study, it was seen that the quality of support, regardless the number of people in the family, was important. The extended family type is more common in families that are dependent on their cultural values in Turkey. Moreover, the process of passing to the small family type to the big family type takes place by being affected from western culture. The small family type is especially common with increased education levels.

In this study, menopausal symptoms were higher in the women with low income as in the case in the relevant literature $(4,10,11,20,33,39,40)$. Poor economic level could affect health-seeking behavior negatively $(10,41)$. Hence, Istanbul is a very huge and expensive city and it has transportation problems. Even if women with poor education level apply to menopause clinics, they are hesitant to share information about their emotional state with healthcare personnel. Additionally, there is a culture of sexuality and emotion in the Turkish family structure, often not shared with healthcare personnel and waiting for problems to be solved spontaneously by themselves.

Psychosocial interventions in coping with physical, psychologic and social changes in women in their menopausal period could provide benefits for the quality of life of women and better health outcomes. Psychosocial interventions should be supplied in healthcare services for women as a part of comprehensive care $(6,17,26,42-44)$. Thus, women should be examined not only about their menopausal symptoms but also about their mood within a holistic view. In this study, we evaluated the loneliness statuses of women in their menopausal period. However, we did not carry out any intervention about how a woman copes with this period or how these issues should be managed. As in other diseases, early recognition of mental problems is very important, and besides physical symptoms, mental health of women in the menopausal period should be follow up. A lot of women who are not able to receive sufficient healthcare services have to take care of themselves in their menopausal period, which is a fragile stage in terms of mental health. So, we thought that every woman in their menopausal period should receive holistic healthcare services, even though it is not possible within Turkey's conditions.

\section{CONCLUSION}

It was determined that women who had high loneliness levels experienced menopausal symptoms more severely, and menopausal symptoms increased with increased loneliness levels. Menopausal symptoms were higher in women who had low education levels, lived in big families, did not have a regular job, had low income. Loneliness was felt more intensely in women with lower levels of education, less regular employment and lower economic income.

In this study, loneliness was found to be an important predictor of the severity of menopause symptoms. The common risk group for both loneliness and menopause symptoms was low education, non-working and low income women. Women in the risk group should be follow up more closely and early interventions to protect mental health should be done.

That the study data were based on self-reporting is an important limitation in the research. It should not be forgotten that the function of the scales and of its scores are meant to serve as a guide to psychotherapists and physician. Another important limitation to the study was that it was conducted at one hospital and did not include women from outside these facilities. Because the study only encompassed information gleaned from women applying to the one hospital in Istanbul, this data cannot be generalized to all women in the menopause stage. 


\section{REFERENCES}

[1] Birkhaeuser M, Genazzani A.R, Editors. Pre-Menopause, Menopause and Beyond: Vol 5: Frontiers in Gynecological Endocrinology, Springer International Publishing AG, Cham, Switzerland, 2018.

[2] Sahin NH. Climacteric Period and Menopause, Kizilkaya Beji N. Editor. Women's Health and Diseases, Istanbul: Nobel Medical Bookstores; 2. Edition, 2016. pp.135-142.

[3] Northrup C. The Wisdom of Menopause: Creating Physical and Emotional Health During the Change, New York, United States, Random House, USA, 2012.

[4] Geukes M, Aalst MP, Robroek SJW, Laven JEE. Oosterhof H. The impact of menopause on work ability in women with severemenopausal symptoms. Maturitas 2016;90:3-8.

[5] Munhoz LO, Sorpreso ICE, Nogueira MCC, Simões RS, Soares Junior JM, Baracat EC. How to evaluate quality of life in overweight and obese women during climacterium? Rev Assoc Med Bras 2014;60(5):484-489.

[6] Karlidere T, Ozsahin A. The Relationship of Menopausal Symptomatology with Anxiety and Depression Levels and Social Supports. J Clin Psy 2008;11(4):159-166.

[7] Kocak DY, Kaya IG, Aslan E. Level Of Social Support Perceived By ClimactericWomen And Affecting Factors. Journal of Academic Research in Nursing (JAREN) 2017;3(2):66-72.

[8] Ovsyanik OA. Social-Psychological Change of Women In Climacteric Period. Psychology and Sociology Sciences 2016;28(2):45-46.

[9] Brown L, Bowden S, Bryant C, Brown V, Bei B, Gilson KM, Komiti $A$, Judd F. Validation and utility of the Attitudes to Ageing Questionnaire: Links to menopause and well-being trajectories. Maturitas 2015;82(2):190-196.

[10] Koyun A, Taskin L, Terzioglu F. Women Health and Psychological Functioning in Different Periods of Life: Evaluation of Nursing Approach. Current Approaches in Psychiatry 2011;3(1):67-99.

[11] Dokmen ZY, Menopause, Body Image and Mental Health. Turkish Psychological Articles 2009;12(24):41-55.

[12] Dellú MC, Schmitt AC, Cardoso MR, Pereira WM, Pereira EC, Vasconcelos Éda S, Aldrighi JM. Prevalence and factors associated with urinary incontinence in climacteric. Rev Assoc Med Bras 2016;62(5):441-446.

[13] Sorpreso ICE, Júnior JMS, Fonseca AM, Baracat EC. Female aging. Rev Assoc Med Bras 2015; 61(6):553-556.

[14] Jaremka LM, Fagundes CP, Peng J, Belury MA, Andridge RR, Malarkey WB, Kiecolt-Glaser JK. Loneliness predicts postprandial ghrelin and hunger in women. Horm Behav 2015;70:57-63.

[15] Fernández A.A, Trabalón-Pastora $M$, Varaa C, Chedrauib P, Pérez-López FR; Menopause Risk Assessment (MARIA) Research Group. Life satisfaction, loneliness and related factors during female midlife. Maturitas 2012;72(1):88-92.

[16] Thurston R, Kubzansky LD. Women, Loneliness, and Incident Coronary Heart Disease. Psychosom Med 2009;71(8): 836842.

[17] Hu L, Zhu L, Lyu J, Zhu W, Xu Y, Yang L. Benefits of Walking on Menopausal Symptoms and Mental Health Outcomes among Chinese Postmenopausal Women. International Journal of Gerontology 2017;11:166-170.

[18] Gurkan OC. The Validity And Reliability of Turkish Version of Menopouase Rating Scale. Journal of Nursing Forum 2005;3035.
[19] Demir A. Validity and Reliability of the U.C.L.A. Loneliness Scale, Turkish Journal of Psychology 1989;7(23):14-18.

[20] Bal MD, Sahin NH. The effects of personality traits on quality of life. Menopause 2011;18(12):1309-1316.

[21] Strezova A, O'Neill S, O'Callaghan C, Perry A, Liu J, Eden J. Cultural issues in menopause: an exploratory qualitative study of Macedonian women in Australia. Menopause 2016; 24(3):308-315.

[22] Theeke LA, Mallow JA, Barnes ER, Theeke E. The Feasibility and Acceptability of LISTEN for Loneliness. Open J Nurs 2015;5(5):416-425.

[23] Zali M, Farhadi A, Soleimanifar M, Allameh H, Janani L. Loneliness, fear of falling, and quality of life in communitydwelling older women who live alone and live with others, Educational Gerontology 2017;43(11):582-588.

[24] Reding KM, Schmidt PJ, Rubinow DR. Perimenopausal depression and early menopause: cause or consequence? Menopause 2017;24(12):1333-1335.

[25] Rossler W, Ajdacic-Gross V, Riecher-Rossler A, Angst J, Hengartner MP. Does menopausal transition really influence mental health? Findings from the prospective long-term Zurich study. World Psychiatry 2016;15(2):146-154.

[26] Núñez-Pizarro JL, González-Luna A, Mezones-Holguín E, Blümel JE, Barón G, Bencosme A, Benítez Z, Bravo LM, Calle $A$, Flores $D$, Espinoza $M T$, Gómez $G$, Hernández-Bueno JA, Martino M, Lima S, Monterrosa A, Mostajo D, Ojeda E, Onatra W, Sánchez $H$, Tserotas $K$, Vallejo MS, Witis $S$, Zúñiga MC, Chedraui P. Association between anxiety and severe qualityof-life impairment in postmenopausal women: analysis of a multicenter Latin American cross-sectional study. Menopause 2017;24(6):645-652.

[27] Soares CN. Mood disorders in midlife women: understanding the critical window and its clinical implications. Menopause 2014;21(2):198-206.

[28] Campbell KE, Dennerstein L, Finch S, Szoeke CE. Impact of menopausal status on negative mood and depressive symptoms in a longitudinal sample spanning 20 years. Menopause 2016;24(5):490-496.

[29] Salazar-Pousada D, Monterrosa-Castro A, Ojeda E, Sánchez SC, Morales-Luna IF, Pérez-López FR, Chedraui P; Research Group for the Omega II Women's Health Project. Evaluation of depressive symptoms in mid-aged women. Menopause 2017;24(11):1282-1288.

[30] Mauas V, Kopala-Sibley DC, Zuroff DC. Depressive symptoms in the transition to menopause: the roles of irritability, personality vulnerability, and self-regulation. Arch Womens Ment Health 2014;17(4):279-289.

[31] Taylor VJ, Hickey M. Menopause and depression: is there a link? Maturitas 2014;79(2):142-146.

[32] Goncalves B, Fagulha T, Ferreira A. A population-based assessment of the relationship between menopausal and depressive symptoms in Portuguese women. Health Care Women Int 2013;34(1):86-100.

[33] Lee $\mathrm{Y}, \mathrm{Kim} \mathrm{H}$. Relationships between menopausal symptoms, depression, and exercise in middle-aged women: A crosssectional survey. International Journal of Nursing Studies 2008;45:1816-1822.

[34] Evlice YE, Tamam L, Karatas G. Psychiatric problems related with menopause and its treatment. Anatolian Journal of Psychiatry 2002;3:108-112. 
[35] Mirhaghjou SN, Niknami M, Moridi M, Pakseresht S, Kazemnejad E. Quality of life and its determinants in postmenopausal women: a population-based study. Appl Nurs Res 2016;30:252-256.

[36] Jaber RM, Khalifeh SF, Bunni F, Diriye MA. Patterns and severity of menopausal symptoms among Jordanian women. J Women Aging 2017; 29(5):428-436.

[37] Li RX, Ma M, Xiao XR, Xu Y, Chen XY, Li B. Perimenopausal syndrome and mood disorders in perimenopause: prevalence, severity, relationships, and risk factors. Medicine (Baltimore) 2016;95(32):e4466.

[38] Zhang Y, Zhao X, Leonhart R, Nadig M, Hasenburg A, Wirsching $\mathrm{M}$, Fritzsche K. A Cross-cultural comparison of climacteric symptoms, self-esteem, and perceived social support between Mosuo women and Han Chinese women. Menopause 2016;23(7):784-791.

[39] Brown L, Bryant C, Brown V, Bei B, Judd F. Investigating how menopausal factors and self-compassion shapewell-being: An exploratory path analysis. Maturitas 2015;81:293-299.

[40] Whiteley J, DiBonaventura Md, Wagner JS, Alvir J, Shah S. The impact of menopausal symptoms on quality of life, productivity, and economic outcomes. J Womens Health (Larchmt) 2013;22(11):983-990.

[41] Kelleci M, N Asti, L Kucuk. Psychological Status Of Women Who Applied To The District Health Center According To The General Health Questionnaire. Journal Of Cumhuriyet University School of Nursing 2003;7(2):11-14.

[42] Vélez Toral M, Godoy-Izquierdo D, Padial García A, Lara Moreno R, Mendoza Ladrón de Guevara N, Salamanca Ballesteros A, de Teresa Galván C, Godoy García JF. Psychosocial interventions in perimenopausal and postmenopausal women: A systematic review of randomised and non-randomised trials and noncontrolled studies. Maturitas 2014;77:93-110.

[43] Im EO, Kim S, Ji X, Park S, Chee E, Chee W, Tsai HM. Improving menopausal symptoms through promoting physical activity: a pilot Web-based intervention study among Asian Americans. Menopause 2017;24(6):653-662.

[44] Coban A, Nehir S, Demirci H, Ozbasaran F, Inceboz U. The Impact on Menopausal Symptoms of Marital Adjustment and Attitude Toward Menopausal of Married Women in The Climacteric Period. Firat University Medical Journal of Health 2008;22(6):343-349.

How to cite this article: Bingol F. B., Bal M. D., Esencan T. Y., Abbasoglu D. E. The Effects of Loneliness on Menopausal Symtoms. Clin Exp Health Sci 2019; 9: 265-270. DOI: 10.33808/clinexphealthsci.533511 